DE

M E D I C I N A

T R O P I C A L

$\mathrm{DE}$

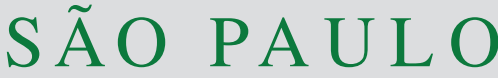

JOURNAL OF THE SÃO PAULO INSTITUTE OF TROPICAL MEDICINE

${ }^{1}$ Hospital Alemão Oswaldo Cruz, Serviço de Controle de Infecção Hospitalar, São Paulo, São Paulo, Brazil

${ }^{2}$ Neoprospecta Microbiome Technologies, Florianópolis, Santa Catarina, Brazil

${ }^{3}$ Fleury Medicina e Saúde, Seção de Microbiologia, São Paulo, São Paulo, Brazil

${ }^{4}$ Universidade de Campinas, Instituto de Biologia, Departamento de Genética, Evolução, Microbiologia e Imunologia, Campinas, São Paulo, Brazil

${ }^{5}$ Universidade de São Paulo, Faculdade de Medicina, Departamento de Moléstias Infecciosas e Parasitárias, São Paulo, São Paulo, Brazil

Correspondence to: Ícaro Boszczowski Hospital Alemão Oswaldo Cruz, Serviço de Controle de Infecção Hospitalar, Rua João Julião, 331, CEP 05403-000, São Paulo, SP, Brazil

Tel: + $55113549-0440$

E-mail: icaro.bski@ haoc.com.br

Received: 16 May 2020

Accepted: 6 August 2020

\section{How new molecular tools can help bugbusters: a Burkholderia cepacia complex outbreak investigation}

\author{
Amanda Luiz Pires Maciel ${ }^{1}$, Cristiane Schmitt ${ }^{1}$, Marcia Maria Baraldi ${ }^{1}$, Caio \\ de Lima Silva1, Luiz Felipe Valter de Oliveira², Jorge Luiz Mello Sampaio, \\ Rogerio Ferreira Lourenço ${ }^{4}$, Anna Sara Levin ${ }^{5}$, Icaro Boszczowski ${ }^{\circledR}{ }_{1}$
}

\section{ABSTRACT}

An outbreak of bloodstream infection (BSI) caused by members of the Burkholderia cepacia complex (Bcc) took place from March 2012 until April 2014 involving thirteen patients. Aim. To describe an outbreak investigation of BSI Bcc and showing how genetic sequencing tools contributed to confirm the hypothesis of extrinsic contamination proposed by an observational study. Methods. The Infection Control Department revised and reinforced good practices of infusion therapy and catheter care, visits to affected wards, a case control study, and environmental screening based on the case-control findings. Results. Data from the case-control study found an association of cases with central venous catheter (OR 1.36; CI 1.15-1.67) and intravenous cisatracurium use (OR 10.75; CI 1.67-68.89). Visits to the operatory block revealed problems related to the cold chain used for the preservation of thermolabile cisatracurium. We could not retrieve Bcc from environmental samples using classic microbiology. New samples from the same surfaces were obtained for genetic sequencing. Bcc was identified in the cooler box, refrigerator and reusable ice packages. Conclusion. Environmental screening using genetic sequencing proved to be a useful tool for confirming our hypothesis of extrinsic contamination raised by the case-control study.

KEYWORDS: Burkholderia cepacia. Outbreak investigation. Bloodstream infection. Next generation sequencing.

\section{INTRODUCTION}

Burkholderia cepacia complex (Bcc) is a group with, at least by the time of writing this report, 22 closely related species with different biological characteristics ${ }^{1,2}$. An accurate differentiation of species using classical bacterial identification techniques is particularly difficult because they are phenotypically very similar. Several molecular techniques, for instance whole-cell protein electrophoresis, rRNA gene-based analysis, 16S rRNA gene-based analysis, multilocus sequence analysis and recA gene have been used as an attempt to differentiate these species ${ }^{1}$. Moreover, classical microbiology has a poor sensitivity for recovering Bcc from the environment ${ }^{2}$.

These agents are widely distributed (soil, water, and rhizosphere) due to their remarkable metabolic versatility ${ }^{3}$. They are opportunistic pathogens among immunocompromised patients commonly causing respiratory tract illness in cystic fibrosis patients, and chronic granulomatous disease ${ }^{3}$. B. cenocepacia and $B$. multivorans are species with most clinical importance in this population ${ }^{3}$. Other members of Bcc are also important pathogens in healthcare-associated 
infections like B. contaminans and B. cepacia have been described in non-cystic fibrosis patients ${ }^{4-6}$. Many outbreaks involving these bacteria have been reported. The most common sources of transmission were moist environmental sources, intravenous contaminated medication and other contaminated substances ${ }^{4,7,8}$.

We observed, at our hospital, a persistent increase of bloodstream infection caused by Bcc (BSI Bcc) initiated in March 2012. Before this period, we had only identified sporadic cases of respiratory infections due to Bcc. Retrospectively reviewing cases of bacteremia over the previous five years showed that there had been only one case of BSI Bcc reported. Thus, we aim to describe an outbreak investigation of BSI Bcc and show how genetic sequencing tools contributed to confirm the hypothesis of extrinsic contamination proposed by an observational study.

\section{MATERIALS AND METHODS}

\section{Setting}

This study was conducted at a 357-bed private tertiary care hospital located in the city of Sao Paulo, Brazil from 2012 to 2014. This hospital is a reference center for surgery with emphasis on oncology. Nearly 14,000 surgeries are performed every year. Only individuals older than 18 years are admitted and there is an intensive care unit with 42 beds.

We divided the description of the investigation into three phases:

\section{Phase 1 (January 2012 - September 2013)}

Ten cases occurred in this period. The outbreak was identified in November 2012 after an observation of an unusually high number of bloodstream infections (BSI) caused by Bcc over the year (Figure 1). Initially, the case definition considered any patient who presented with a Bcc infection identified in a blood culture that was not present at hospital admission, occurring between January and September 2012. Cases took place in different wards: surgical and medical, including the intensive care unit. We immediately proposed revision of good practices related to central line care such as: (i) revision of CVC (central venous catheter) insertion techniques, including skin preparation and maximal barrier involving nursing and medical staff; (ii) CVC exit site care; (iii) intravenous drugs handling and administration. Concomitantly, we conducted a descriptive epidemiological analysis searching for common exposures. Nothing was revealed by this initial analysis. Afterwards, there was a three-month period with no cases, then new BSIs occurred suggesting an ongoing transmission. We then decided to perform a case-control study. Cases were then re-defined as an inpatient diagnosed with bloodstream infection (BSI) caused by Bcc that occurred between March 2012 and May 2013 in any unit of the hospital. BSI should necessarily have been diagnosed after 48 hours of hospital admission and could not have been related to a previous admission (less than one month since previous hospital discharge). We included all BSI (central line associated bloodstream infections and those which were secondary

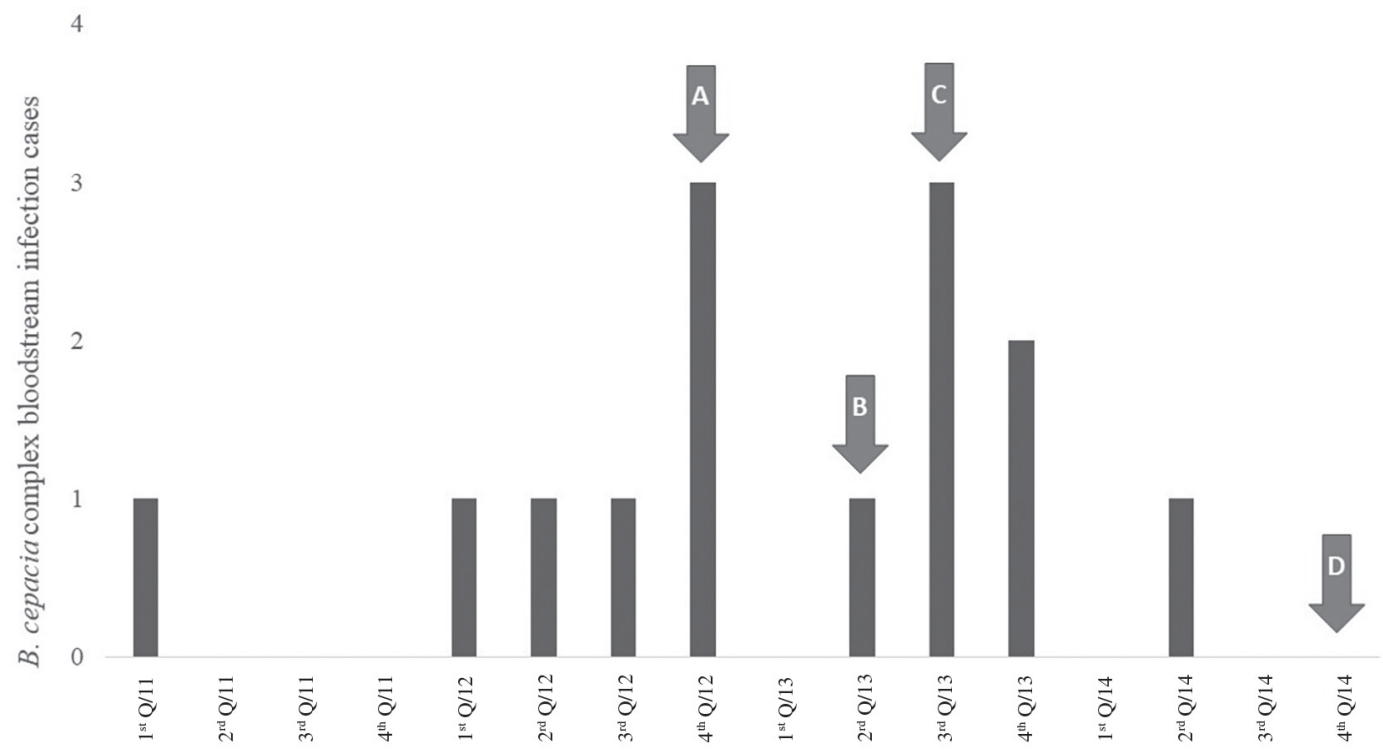

Figure 1 - Description of the occurrence of bloodstream infections caused by B. cepacia complex between March 2012 and November 2014: A) Detection of the outbreak; B) Case control study; C) Visits to operatory block and environmental screening (classical microbiology); D) Environmental screening (genetic sequencing). The case of January 2011 was not considered related to this outbreak. 
to another source) using the $\mathrm{CDC}$ criteria ${ }^{9}$. Controls were selected among patients who shared the same ward with a case for at least seven days within the same month of the infection.

Medical charts were reviewed and the following information was recorded: sex; age; underlying diseases; date of hospital admission; date of BSI; ward; central venous catheter (CVC) insertion; type of CVC; antiseptic used during CVC handling; use of urinary catheter, mechanical ventilation, tracheostomy, nasogastric or nasoenteral tube, surgery, parenteral nutrition, endoscopic procedures, dialysis, medical imaging exams. All solutions and medications administered intravenously for cases and controls were listed.

\section{Phase 2 (October - December 2013)}

Two cases occurred in this period. Univariate analysis of the case-control study showed an association between cisatracurium, nalbuphine and propofol use and Bcc BSI. Thus, we decided to track the pathway of these drugs. Moreover, we extended the case-control study including cases occurring until December 2013.

In October 2013, screening of the environment using classical microbiological methods was carried out. Environmental samples were obtained from equipment related to anesthesia drugs such as acrylic storage box, anesthesia trolley, infusion pump, and the cold chain used for storage of thermolabile anesthesia drugs (freezer, refrigerator, coolers, and ice packages).

\section{Phase 3 (January to November 2014)}

One case occurred in this period. New environmental samples were obtained for genetic sequencing. The operatory block was revisited for checking the implementation of new procedures recommended by the infection control team.

\section{Microbiology}

Clinical samples: blood cultures were obtained at the discretion of the assistant physician for clinical decision purposes and inoculated into Bactec Aerobic Plus vials. Positive vials were subcultured on sheep blood agar and colonies were identified by mass spectrometry (Microflex Bruker, Madison, USA). Species or complex identification were considered adequate if the score was $\geq 2.0$. Isolates with identification score $<2.0$ were retested and or identified by rRNA $16 \mathrm{~S}$ gene sequencing.

Environmental samples culture: sixteen samples were obtained by the hospital infection control team using sterile swabs, which were previously moistened with sterile saline solution and rubbed against surfaces. Swabs were inoculated into TSB broth containing vancomycin $(2 \mathrm{mg} / \mathrm{L})$ and ertapenem $(1 \mathrm{mg} / \mathrm{L})$ and were incubated at $35{ }^{\circ} \mathrm{C}$ in ambient air for up to seven days. Vials were inspected daily and subcultured on sheep blood agar when turbid. Colonies grown on solid media were identified by mass spectrometry (Microflex - Bruker, Madison, USA).

\section{DNA Sequencing}

Forty-two environmental samples were collected by the hospital infection control team using sterile swabs moistened with sterile water. The DNA was extracted directly from swabs and used to perform 16S ribosomal RNA gene (16S rRNA) sequencing, as previously described ${ }^{10}$. The sequencing libraries were prepared following a two-step PCR protocol. Firstly, the V3-V4 regions of 16S rRNA were amplified using Taq Platinum DNA polymerase (Invitrogen, USA) and the primers $314 \mathrm{~F}$ and $806 \mathrm{R}$ containing the Illumina adapter overhanging nucleotide sequences ${ }^{11}$. Then, a second PCR step was carried out to attach dual indices and Illumina sequencing adapters to the amplicons produced in the first PCR reaction. The final PCR products were cleaned up using AMPureXP beads (Beckman Coulter, Brea, CA, USA), and quantified using both Picogreen dsDNA assay (Invitrogen, California, USA) and KAPA Library Quantification Kit (KAPA Biosystems, Woburn, MA, USA). In parallel to the samples, a negative control was processed. The libraries were pooled equivolumetrically to maintain the relationship of the original amount of DNA. The libraries were sequenced in a MiSeq system according to instructions previously described ${ }^{12}$. After demultiplexing and trimming, quality filter reading was performed converting each nucleotide Q score into error probability, that was summed. If accumulated error was lower or equal to $0.01(1 \%)$ the reading was considered in downstream analysis. To increase the reliability of the reading, excluding possible diversity generated by chimeric amplicons or erroneous nucleotide incorporated in PCR, we used the information of amplicon single variants (ASVs) in 100\% identical oligotype clusters. If any cluster is represented by fewer than 5 readings, it was not considered in further analysis. Additionally, a denoise process was performed with Deblur ${ }^{13}$. The resulting sequences were compared with the rRNA16S database (NeoRefdb, Neoprospecta Microbiome Technologies, Brazil) and classified as previously described ${ }^{14}$. The oligotypes founded for B. cepacia complex was aligned with Clustal Omega (version 1.2.4, Science Foundation Ireland, Dublin, Ireland) and the phylogeny was performed using FastTree. 


\section{Statistics}

Data for the case-control study retrieved from medical charts were analyzed by using EPI Info v7.1.5.2 (Centers for Disease Control and Prevention, Atlanta, GA, USA). Student $t$ test and Fisher exact test were used when appropriate. Multivariate analysis was performed by using logistic regression for all variables with $p<0.15$ in the univariate analysis.

\section{RESULTS}

\section{Outbreak description and patient characteristics}

Between March 2012 and April 2014, we identified 13 bloodstream infections in the intensive care unit and other nine different wards. The epidemic curve is presented in Figure 1. We revised the infection control database, and during the last 5 years before March 2012, we had only one BSI caused by the B. cepacia complex.

The mean age of the patients was 72 years (range: 39-93), nine of 13 cases were male, and 11 had undergone a procedure at the surgical block in the last 39 days (mean: 15.7 days; range: 1-39). We had 1.8 positive blood cultures for each patient (varying from one to three positive samples). Clinical demographic data and outcomes are presented in Table 1.

\section{Phase 1}

Our initial univariate analysis of the case-control study, involved seven bacteremic cases and 35 controls, pointed to

Table 1 - Clinical characteristics of patients with bloodstream infection caused by Burkholderia cepacia complex.

\begin{tabular}{|c|c|c|c|c|c|c|c|c|c|}
\hline Patient & Sex & Age & $\begin{array}{l}\text { Underlying } \\
\text { disease }\end{array}$ & $\begin{array}{l}\text { Procedure performed } \\
\text { at surgical block }\end{array}$ & $\mathrm{BSI}$ & $\begin{array}{c}\text { Time } \\
\text { between } \\
\text { surgery and } \\
\text { BSI (days) }\end{array}$ & Outcome & $\begin{array}{c}\text { Use of } \\
\text { anesthesia } \\
\text { drugs }^{\dagger}\end{array}$ & $\begin{array}{c}\text { Use of } \\
\text { Cisatracurium }\end{array}$ \\
\hline 1 & M & 79 & $\begin{array}{c}\text { Coronary } \\
\text { artery disease }\end{array}$ & $\begin{array}{c}\text { Biliary drainage } \\
\text { post gastroduodeno } \\
\text { pancreatectomy }\end{array}$ & 07/03/2012 & 25 & Death & Yes & Yes \\
\hline 2 & M & 68 & Osteoarthritis & $\begin{array}{l}\text { Knee Replacement } \\
\text { Revision Surgery }\end{array}$ & $16 / 05 / 2012$ & 12 & Survival & Yes & No \\
\hline 3 & M & 81 & Lung cancer & Spinal arthrodesis & 05/08/2012 & 20 & Death & Yes & Yes \\
\hline 4 & M & 79 & $\begin{array}{l}\text { Cardiac heart } \\
\text { failure }\end{array}$ & - & 05/10/2012 & - & Survival & Yes & No \\
\hline 5 & $\mathrm{~F}$ & 69 & Stroke & $\begin{array}{l}\text { Short- term central } \\
\text { venous catheter } \\
\text { insertion }\end{array}$ & $18 / 10 / 2012$ & 39 & Survival & Yes & No \\
\hline 6 & M & 52 & Gastric cancer & Gastrectomy & $18 / 12 / 2012$ & 6 & Survival & Yes & No \\
\hline 7 & $\mathrm{~F}$ & 52 & COPD & - & 08/04/2013 & - & Survival & Yes & No \\
\hline 8 & M & 93 & $\begin{array}{l}\text { Hypertension, } \\
\text { diabetes } \\
\text { mellitus }\end{array}$ & Colectomy & 06/07/2013 & 19 & Survival & Yes & Yes \\
\hline 9 & $\mathrm{~F}$ & 70 & $\begin{array}{l}\text { Osteoarthritis, } \\
\text { COPD }\end{array}$ & knee arthroscopy & 03/08/2013 & 7 & Survival & Yes & Yes \\
\hline 10 & M & 67 & $\begin{array}{l}\text { Colorectal } \\
\text { cancer }\end{array}$ & Retossigmoidectomy & 07/09/2013 & 18 & Survival & Yes & No \\
\hline 11 & $M$ & 77 & Pneumonia & $\begin{array}{l}\text { Short- term central } \\
\text { venous catheter } \\
\text { insertion }\end{array}$ & $13 / 10 / 2013$ & 18 & Survival & Yes & No \\
\hline 12 & M & 74 & Penis Cancer & $\begin{array}{l}\text { Long-term central } \\
\text { venous catheter } \\
\text { insertion }\end{array}$ & 22/12/2013 & 8 & Survival & Yes & No \\
\hline 13 & $\mathrm{~F}$ & 85 & $\begin{array}{l}\text { End-stage } \\
\text { renal disease }\end{array}$ & $\begin{array}{l}\text { Long-term central } \\
\text { venous catheter } \\
\text { insertion }\end{array}$ & $26 / 04 / 2014$ & 1 & Death & Yes & No \\
\hline
\end{tabular}

${ }^{\dagger}$ Propofol, Cisatracurium, Nalbuphine, and Fentanyl; CVC = central venous catheter; $\mathrm{F}=$ female; $\mathrm{M}=$ male; COPD = chronic obstructive pulmonary disease; $\mathrm{BSI}$ = bloodstream infection 
cisatracurium, nalbuphine and propofol use as potential risk factors ( $p=0.04,0.01$, and 0.03 respectively). Hence, we decided to perform visits to the operatory block (described below in phase 2 results) as this was the main unit using cisatracurium.

\section{Phase 2}

Based on the first case-control findings, the infection control team visited the operatory block in October 2013 to evaluate the use of cisatracurium. This is a drug used during anesthesia for neuromuscular blockage and to improve ventilation management during surgery. It requires refrigeration at 2 to $8{ }^{\circ} \mathrm{C}^{15}$.

During the visit to the operatory block we identified that the routine cleaning procedures of freezer, reusable ice packs, boxes that carried anesthetic drugs and anesthesia trolley were not well established or written; many of these items were not reprocessable (cooler boxes, ice packs) but were being reused.

Thermolabile drugs were inadequately stored in the refrigerator (which was rusty). Routine procedures for cleaning equipment were written and implemented; nonreusable equipment was discarded after a single use, a new refrigerator was installed, a routine for adequate storage of thermolabile drugs was implemented.

Cisatracurium usage: the batches of cisatracurium used in all patients involved in the outbreak were tracked. There were so many different batches that none could be implicated. For this reason, we neither discontinued its use nor laboratory tested any batch number.

Environmental microbiological screening: no Bcc isolates grew in samples obtained from the environment.

Case-control study: the final analysis of the case-control study included 57 patients with a case-control ratio of 1:4. The following risk factors were identified in the univariate analysis: use of CVC, mechanical ventilation, tracheostomy, piperacillin-tazobactam, meropenem, sulfamethoxazoletrimethoprim, propofol, cisatracurium and nalbuphine (Table 2).

In the multivariate analysis only CVC (OR: $1.36 ; 95 \%$ CI 1.15-1.67) and intravenous cisatracurium (OR: 10.75; 95\% CI 1.67-68.89) were associated with BSI Bcc.

Table 2 - Univariate analysis of patient characteristics and potential risk factors for Burkholderia cepacia complex bloodstream infection.

\begin{tabular}{|c|c|c|c|c|}
\hline Potential risk factors & $\begin{array}{l}\text { Case } \\
\mathrm{N}=12\end{array}$ & $\begin{array}{l}\text { Control } \\
\mathrm{N}=45\end{array}$ & $\begin{array}{l}\text { Unadjusted odds ratio } \\
\text { (95\% confidence interval) }\end{array}$ & $\mathrm{p}$ value \\
\hline \multicolumn{5}{|l|}{ Invasive procedures } \\
\hline Tracheostomy & $4(33 \%)$ & $31(69 \%)$ & $0.21(0.05-0.91)$ & 0.05 \\
\hline Mechanical Ventilation & $5(42 \%)$ & $35(77 \%)$ & $0.21(0.05-0.8)$ & 0.02 \\
\hline Central venous catheter & $12(100 \%)$ & $31(69 \%)$ & $1.6(1.2-2)$ & 0.03 \\
\hline Surgery & $8(67 \%)$ & $32(71 \%)$ & $1.21(0.25-8.08)$ & 1 \\
\hline Any diagnosis image during surgery & $2(17 \%)$ & $2(4 \%)$ & $5.5(0.88-33.9)$ & 0.06 \\
\hline \multicolumn{5}{|l|}{ Antimicrobial drugs } \\
\hline Linezolid & $2(16 \%)$ & - & $4.65(1.08-19.86)$ & 0.05 \\
\hline Piperacillin-tazobactam & $7(58 \%)$ & $2(2 \%)$ & $5.75(1.5-21.73)$ & 0.01 \\
\hline Teicoplanin & $4(33 \%)$ & $4(4 \%)$ & $4.65(1.08-19.86)$ & 0.05 \\
\hline Meropenem & $7(58 \%)$ & $16(36 \%)$ & $5.75(1.52-21.73)$ & 0.01 \\
\hline Fluconazole & $5(42 \%)$ & $9(20 \%)$ & $3.37(0.95-11.87)$ & 0.10 \\
\hline Cefuroxime & $3(25 \%)$ & $5(11 \%)$ & $3.52(0.79-15.53)$ & 0.11 \\
\hline Sulfamethoxazole-trimethoprim & $3(25 \%)$ & $4(9 \%)$ & $6.02(1.43-25.32)$ & 0.02 \\
\hline Liposomal Amphotericin B & $1(8 \%)$ & $2(2 \%)$ & Undefined & 0.21 \\
\hline \multicolumn{5}{|l|}{ Other drugs } \\
\hline Fentanyl & $8(67 \%)$ & $20(44 \%)$ & $2.93(0.83-10.25)$ & 0.13 \\
\hline Midazolam & $7(58 \%)$ & $19(42 \%)$ & $3.17(0.85-11.78)$ & 0.12 \\
\hline Propofol & $7(58 \%)$ & $17(38 \%)$ & $4.21(1.18-14.96)$ & 0.03 \\
\hline Cisatracurium & $4(33 \%)$ & $2(4 \%)$ & $15.45(1.62-146.94)$ & 0.008 \\
\hline Promethazine & $1(8 \%)$ & - & Undefined & 0.09 \\
\hline Nalbuphine & $2(17 \%)$ & - & Undefined & 0.02 \\
\hline \multicolumn{5}{|l|}{ Other infusion substances } \\
\hline Parenteral nutrition & $3(25 \%)$ & $7(16 \%)$ & $3.56(0.95-13.23)$ & 0.07 \\
\hline Omeprazole & $3(25 \%)$ & $6(13 \%)$ & $4.65(1.08-19.86)$ & 0.05 \\
\hline
\end{tabular}




\section{Phase 3}

New environmental samples collected from the same surfaces previously described were submitted to genetic sequencing. Through this analysis, we were able to access the environmental microbiome profile and seek for occurrence of Bcc. We found two different oligotypes (seq1 and seq2) classified as Bcc in the cooler box, refrigerator and ice packs (Figure 2). Seventy-one other genera were sequenced within the 32 environment samples. After new procedures for adequacy of the cisatracurium cold chain were fully implemented, no new cases of bloodstream infection caused by Bcc were identified.

\section{DISCUSSION}

This study describes an outbreak investigation of BSI $\mathrm{Bcc}$ at a tertiary care hospital. The case-control study pointed to an association between BSI Bcc and cisatracurium use. This thermolabile drug was maintained in a cold chain in the pharmacy of the operatory block. During the visits to the block, we encountered poor hygiene practices along the cold chain for the preservation of thermolabile drugs. Revision of good practices, such as the introduction of cleaning routine and substitution of disposable ice packages resulted in the outbreak control. Although we could not verify clonality for the confirmation of the source of the outbreak, genetic sequencing of environmental samples of the cold chain reinforced our hypothesis raised by the case control study and not confirmed by the classic microbiology.
Bcc outbreaks represents $1 \%$ of all outbreaks related to contaminated substances (e.g. drugs and disinfectants) ${ }^{16}$. Drugs are more likely to be contaminated during manipulation at the patient's site ${ }^{16}$. There are a few Bcc outbreaks published describing extrinsic substance contamination, such as Ringer lactate solution as multipledose vial for catheter flushing ${ }^{17}$, diluted heparin solution ${ }^{18}$, and antiseptics solutions prepared in the hospital ${ }^{19}$.

Because the cisatracurium used in the cases came from many different batches, we ruled out intrinsic contamination of the drug and searched for environmental Bcc contamination along the cold chain. The aerobic culture methods investigation resulted negative. Genetic sequencing allowed us to confirm our hypothesis of environmental contamination. Bcc is difficult to cultivate, especially in samples obtained from environmental surfaces ${ }^{20}$. In the last decade, most of Bcc outbreaks investigations used culturedependent techniques to isolate this pathogen, followed by a molecular technique for species identification. It has been usually successful ${ }^{4,8,17-19}$, but in some cases, such as our investigation, it may not have been enough ${ }^{7,21-23}$. In this context, environmental genetic sequencing is a helpful tool for outbreaks investigation.

Miller et $a l .{ }^{24}$ demonstrated that recovering Bcc from the environment (soil and rhizospheres) based solely on culture has a worse performance compared to DNA extraction. In their study, isolates were recovered from environmental samples by using classical microbiology cultures. After that, isolates were examined by PCR assays targeting Bccspecific ribosomal DNA and recA gene sequences. Bcc were

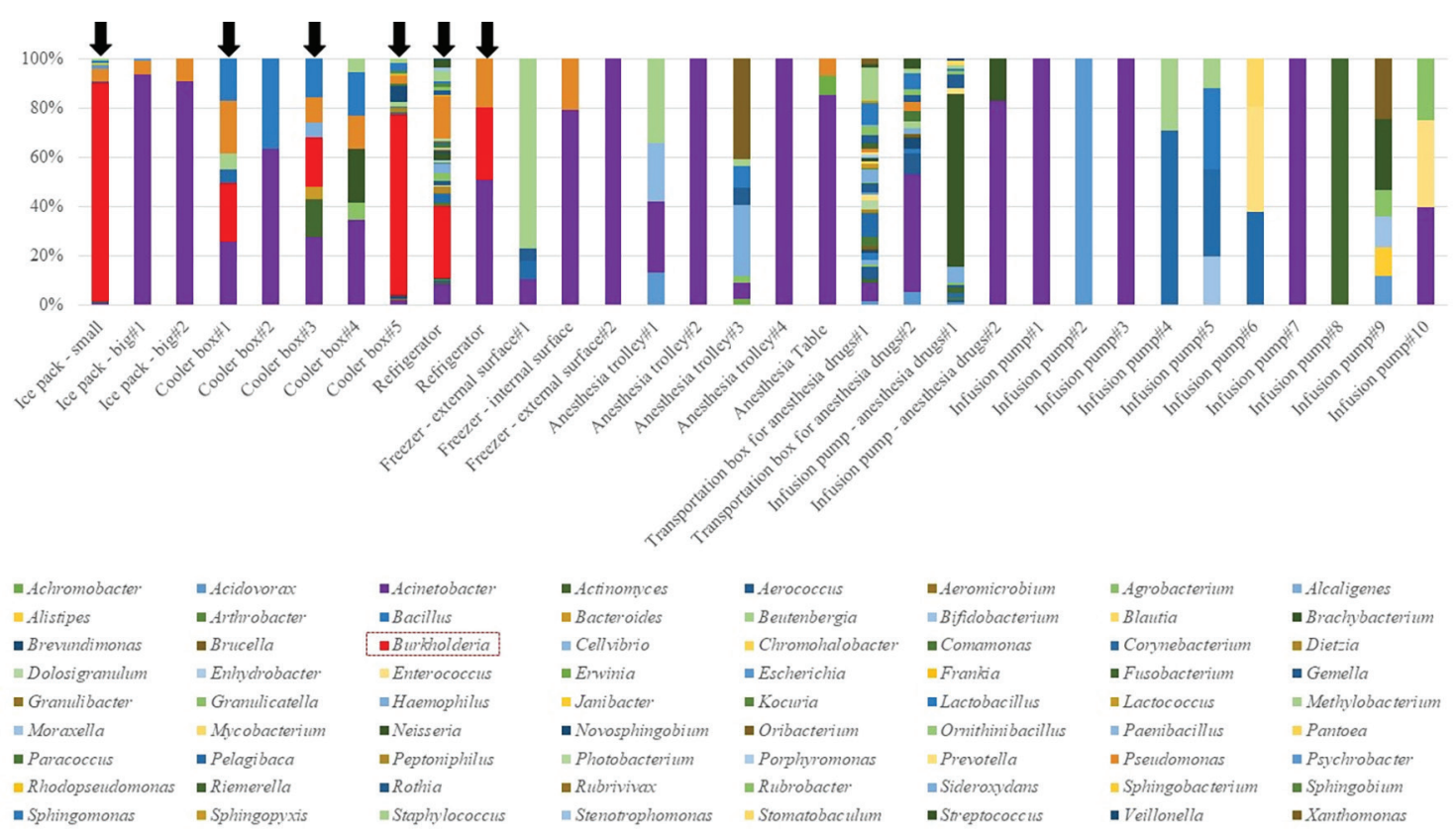

Figure 2 - Composition of bacteria identified by DNA sequencing. Samples were organized by surface types. Relative abundance is shown as percentages. Arrows mean oligotypes for Burkholderia cepacia complex. 
recovered from $15 \%$ of samples. When DNA was extracted directly from environmental samples, around $80-90 \%$ were positive for at least one Bcc genomovar ${ }^{2}$. Pirone et al. ${ }^{25}$ showed that when using the culture-independent method, it is possible to recover a larger diversity of species in the environment.

Bcc sequences were identified along the cisatracuriums' cold chain storage. The recovering of the Bcc sequences may not mean that the bacteria were still viable, even though Bcc are known as a group with a high genomic plasticity allowing their adaptation and survival in diverse habitats for very long periods ${ }^{3}$. The sites where Bcc species were found by environmental 16S rRNA sequencing support the hypothesis of contamination through the cisatracuriums' cold chain storage. We found 71 other genera in 32 other samples. This finding is expected as the environment is not supposed to be sterile. However, the combination of the environmental persistence of Bcc plus poor hygiene practices favored the occurrence of bloodstream infections.

In the clinical context, Bcc identification to species level is a challenge because phenotypical tests available in clinical laboratories are not reliable to differentiate between species. For this reason, molecular techniques are needed to differentiate them. Multilocus sequence-based and recA gene polymerase chain reaction have emerged as effective tools for Bcc identification and classification ${ }^{1}$. Matrixassisted laser desorption ionization-time of flight mass spectrometry (MALDI-TOF MS) has also emerged as a potential tool for identifying species of $\mathrm{Bcc}^{26,27}$.

There are limitations in this study related to the microbiology investigation. Firstly, Bcc recovered from blood samples were not genetically sequenced, thus we could neither identify the Bcc to the species level, nor determine the relatedness between clinical isolates and environmental samples. Cisatracurium was not tested to evaluate contamination. However, the use of different batches among cases, and the cessation of the outbreak after the implementation of infection control measures in the pharmacy and the anesthesia process support the hypothesis of an extrinsic contamination.

The same route of acquisition could not explain two out of 13 cases as these patients were not operated. Nevertheless, the epidemiological link identified in the casecontrol study, Bcc sequences identified in the cold chain, and the effectiveness of control measures implemented, make us believe that the cold chain contamination played a role in the acquisition of this pathogen. We hypothesized that the external surfaces of ampoules were contaminated along the cold chain and several opportunities of central venous catheter and blood contamination occurred during anesthesia via the hands of the anesthesiologists. The anesthesia process poses a high burden of work during a strict timeframe. Compliance to hand hygiene in this scenario has been reported to be as low as $17 \%{ }^{28}$. The anesthesiologist area has been demonstrated to be highly contaminated during surgical procedures what may lead to bloodstream infections after surgery ${ }^{28}$.

\section{CONCLUSION}

In conclusion, we report an outbreak of bloodstream infections caused by Bcc probably due to an extrinsic contamination of cisatracurium ampoules during its storage in cold chain. Culture-based recovery of Bcc in environment was not successful, but environment genetic sequencing identified the source hypothesized during a case-control study.

\section{REFERENCES}

1. Martina P, Leguizamon M, Prieto CI, Sousa SA, Montanaro P, Draghi WO, et al. Burkholderia puraquae sp. nov., a novel species of the Burkholderia cepacia complex isolated from hospital settings and agricultural soils. Int J Syst Evol Microbiol. 2018;68:14-20.

2. Loveridge EJ, Jones C, Bull MJ, Moody SC, Kahl MW, Khan $\mathrm{Z}$, et al. Reclassification of the specialized metabolite producer Pseudomonas mesoacidophila ATCC 31433 as a member of the Burkholderia cepacia complex. J Bacteriol. 2017; 199:JB.00125-17.

3. Mahenthiralingam E, Baldwin A, Dowson CG. Burkholderia cepacia complex bacteria: opportunistic pathogens with important natural biology. J App Microbiol. 2008;104:1539-51

4. Peterson AE, Chitnis AS, Xiang N, Scaletta JM, Geist R, Schwartz $\mathrm{J}$, et al. Clonally related Burkholderia contaminans among ventilated patients without cystic fibrosis. Am J Infect Control. 2013;41:1298-300.

5. Kenna DT, Lilley D, Coward A, Martin K, Perry C, Pike R, et al. Prevalence of Burkholderia species, including members of Burkholderia cepacia complex, among UK cystic and noncystic fibrosis patients. J Med Microbiol. 2017;66:490-501.

6. Tavares M, Kozak M, Balola A, Sá-Correia I. Burkholderia cepacia complex bacteria: a feared contamination risk in water-based pharmaceutical products. Clin Microbiol Rev. 2020;33:e0013919.

7. Nannini EC, Ponessa A, Muratori R, Marchiaro P, Ballerini V, Flynn L, et al. Polyclonal outbreak of bacteremia caused by Burkholderia cepacia complex and the presumptive role of ultrasound gel. Braz J Infect Dis. 2015;19:543-5

8. Martins IS, Pellegrino FL, Freitas AA, Santos MS, Ferraiuoli GI, Vasques MR, et al. Case-crossover study of Burkholderia cepacia complex bloodstream infection associated with 
contaminated intravenous bromopride. Infect Control Hosp Epidemiol. 2010;31:516-21.

9. Centers for Disease Control and Prevention. National Healthcare Safety Network (NHSN) patient safety component manual. Atlanta: CDC; 2018.

10. Christoff AP, Sereia AF, Boberg DR, Moraes RL, Oliveira LF. Bacterial identification through accurate library preparation and high-throughput sequencing. Neoprospecta Microbiome Technologies; 2017. [cited 2020 Aug 11]. Available from: http://neoprospecta.s3.amazonaws.com/docs/Neoprospecta++White+Paper+-+Bacterial+NGS+sequencing+2017.pdf

11. Wang Y, Qian PY. Conservative fragments in bacterial 16S rRNA genes and primer design for $16 \mathrm{~S}$ ribosomal DNA amplicons in metagenomic studies. PLoS One. 2009;4:e7401.

12. Illumina. 16S Metagenomic Sequencing Library Preparation. [cited 2020 Aug 11]. Available from: https://support.illumina.com/ documents/documentation/chemistry_documentation/16s/16smetagenomic-library-prep-guide-15044223-b.pdf

13. Amir A, McDonald D, Navas-Molina JA, Kopylova E, Morton JT, Xu ZZ, et al. Deblur rapidly resolves single-nucleotide community sequence patterns. mSystems. 2017;2:e00191-16.

14. Christoff AP, Cruz GN, Sereia AF, Yamanaka LE, Silveira PP, Oliveira LF. End-to-end assessment of fecal bacteriome analysis: from sample processing to DNA sequencing and bioinformatics results. bioRxiv. 2019;646349.

15. United States of America. Food and Drug Administration. NIMBEX - cisatracurium besylate injection, Abbott Laboratories. [cited 2020 Aug 11]. Available from: https://www.accessdata.fda.gov/ drugsatfda_docs/label/2010/020551s019lbl.pdf

16. Vonberg RP, Gastmeier P. Hospital-acquired infections related to contaminated substances. J Hosp Infect. 2007;65:15-23.

17. De Smet B, Veng C, Kruy L, Khan C, van Griensven J, Peeters C, et al. Outbreak of Burkholderia cepacia bloodstream infections traced to the use of Ringer lactate solution as multiple-dose vial for catheter flushing, Phnom Penh, Cambodia. Clin Microbiol Infect. 2013;19:832-7.

18. Yang CJ, Chen TC, Liao LF, Ma L, Wang CS, Lu PL, et al. Nosocomial outbreak of two strains of Burkholderia cepacia caused by contaminated heparin. J Hosp Infect. 2008;69:398400.
19. Lee S, Han SW, Kim G, Song DY, Lee JC, Kwon KT. An outbreak of Burkholderia cenocepacia associated with contaminated chlorhexidine solutions prepared in the hospital. Am J Infect Control. 2013;41:e93-6

20. Vanlaere E, Coenye T, Samyn E, Van Den Plas C, Govan J, De Baets F, et al. A novel strategy for the isolation and identification of environmental Burkholderia cepacia complex bacteria. FEMS Microbiol Lett. 2005;249:303-7.

21. Shrivastava B, Sriram A, Shetty S, Doshi R, Varior R. An unusual source of Burkholderia cepacia outbreak in a neonatal intensive care unit. J Hosp Infect. 2016;94:358-60.

22. Hanulik V, Webber MA, Chroma M, Uvizl R, Holy O, Whitehead $\mathrm{RN}$, et al. An outbreak of Burkholderia multivorans beyond cystic fibrosis patients. J Hosp Infect. 2013;84:248-51.

23. Abe K, D’Angelo MT, Sunenshine R, Noble-Wang J, Cope J, Jensen B, et al. Outbreak of Burkholderia cepacia bloodstream infection at an outpatient hematology and oncology practice. Infect Control Hosp Epidemiol. 2007;28:1311-3.

24. Miller SC, LiPuma JJ, Parke JL. Culture-based and non-growthdependent detection of the Burkholderia cepacia complex in soil environments. Appl Environ Microbiol. 2002;68:3750-8.

25. Pirone L, Chiarini L, Dalmastri C, Bevivino A, Tabacchioni S. Detection of cultured and uncultured Burkholderia cepacia complex bacteria naturally occurring in the maize rhizosphere. Environ Microbiol. 2005;7:1734-42.

26. Mott T, Soler M, Grigsby S, Medley R, Whitlock GC. Identification of potential diagnostic markers among Burkholderia cenocepacia and B. multivorans supernatants. J Clin Microbiol. 2010;48:4186-92.

27. Fehlberg LC, Andrade LH, Assis DM, Pereira RH, Gales AC, Marques EA. Performance of MALDI-ToF MS for species identification of Burkholderia cepacia complex clinical isolates. Diagn Microbiol Infect Dis. 2013;77:126-8

28. Munoz-Price LS, Bowdle A, Johnston BL, Bearman G, Camins $\mathrm{BC}$, Dellinger EP, et al. Infection prevention in the operating room anesthesia work area. Infect Control Hosp Epidemiol. 2019;40:1-17. 